Hegemonia - Revista Eletrônica de Relações Internacionais do Centro Universitário Unieuro ISSN: 1809-1261

UNIEURO, Brasília, número 20, Janeiro-Junho de 2017, pp. 4-26.

Recebido em: 12/10/2016

Avaliado em: 30/10/2016

Aprovado em: 12/12/2016

\title{
O Programa Cultivando Água Boa: Uma Avaliação Desde a Perspectiva da Colonialidade
}

Aldira Guimarães Duarte Domínguez e Fagner Barbosa Pimentel ${ }^{2}$

Resumo: Este artigo objetiva, primeiramente, compreender as contraditórias formas de tratar o tema Educação Ambiental como promotora de Integração através dos vários modelos existentes de Desenvolvimento Sustentável. Mostra-se a contradição que existe no projeto Cultivando Água Boa $(\mathrm{CAB})$ na sua essência, porque, na medida em que se preocupa com o bem-estar do planeta, por outra parte, a Itaipu, que é a mentora do CAB, recomenda/incentiva ao Brasil e os demais países a construção de mais usinas hidrelétricas. Destaca-se também o antagonismo existente na lógica sustentável cientificista ocidental discursada pela Itaipu em defesa do meio ambiente, pois, ao mesmo tempo em que agride e explora a natureza de forma "ecologicamente correta", destrói a mesma e sua biodiversidade. Verifica-se que por meio da Educação Ambiental o CAB desenvolve um tipo de integração relacional e funcional.

Palavras chave: Cultivando Água Boa, Educação Ambiental, Integração, Sustentabilidade.

Abstract: This article objective, first, to understand the contradictory ways to address the issue Environmental Education as a promoter of integration through the various existing models of sustainable development. We show the contradiction in Cultivating Good Water Project $(\mathrm{CAB})$ in its essence, because, as that is concerned with the welfare of the planet, on the other hand, Itaipu, which is the mentor of the $\mathrm{CAB}$ recommended/encouraged to Brazil and the other countries to build more hydropower plants; also highlighted the antagonism in Western scientistic sustainable logic speech by Itaipu in defense of the environment because, while that attacks and explore the nature in a " green", destroying it and its biodiversity. Secondly we see that through the Environmental Education CAB develops a kind of relational and functional integration.

Keywords: Cultivating Good Water, Environmental Education, Integration, Sustainability.

\footnotetext{
1 Professora Doutora Adjunta IV da Universidade de Brasília, Faculdade de Ceilândia, Curso de Saúde Coletiva. E-mail: aldira_guimaraes@yahoo.com.br

2 Mestrando em Integração Contemporânea da América Latina, ICAL, na Universidade Federal da Integração Latino-americana, UNILA. Bolsistas do Programa de Demanda Social-Unila.

E-mail: fgbarbosapimentel@yahoo.com.br
} 
Artigo Inédito

Hegemonia - Revista Eletrônica de Relações Internacionais do Centro Universitário Unieuro ISSN: 1809-1261

UNIEURO, Brasília, número 20, Janeiro-Junho de 2017, pp. 4-26.

Introdução

Dentre as variadas práticas indiscriminadas de exploração do meio ambiente, uma das mais impactantes são as barragens artificiais construídas para retenção de grandes quantidades de água comumente para o uso na irrigação, abastecimento hídrico de zonas urbanas e rurais, e usinas hidrelétricas. As construções dessas barragens são capazes de transformar a natureza de forma permanente e/ou de modo irrecuperável, motivo de preocupação que traz intensos debates no mundo da ciência e da tecnologia na atualidade.

No que diz respeito a construções de barragens para utilização da água em usinas hidrelétricas sabe-se que:

\begin{abstract}
As usinas hidrelétricas são uma importante fonte de energia no mundo atual, de acordo com o Renewables Global Status Report 2006, no ano de 2005 as usinas hidrelétricas produziram $19 \%$ da eletricidade consumida no mundo todo. A energia produzida pelas usinas hidrelétricas também é o equivalente a cerca de 5 bilhões de barris de petróleo. Segundo a Agência Nacional de Energia Elétrica (ANEEL), o Brasil está entre os cinco maiores produtores de energia hidrelétrica no mundo, possuindo atualmente 158 usinas hidrelétricas de grande porte, que produzem um total de $74.438 .695 \mathrm{~kW}$ (BONSOR, 2008). Esse tipo de geração de energia produz diversos impactos ambientais, o que faz com que seja motivo de polêmica atualmente com o avanço das discussões sobre desenvolvimento sustentável. Os estudiosos procuram descobrir a dimensão deste impacto a fim de encontrar formas de amenizá-los, uma vez que a energia hidrelétrica é considerada fonte renovável (COSTA \& SANTOS, 2012, p. 24).
\end{abstract}

Engenheiros da área de fontes energéticas argumentam que as hidrelétricas são consideradas fontes de energia renovável. No entanto, o método utilizado para avaliar qual tipo de energia é proveniente de fonte limpa e renovável está na sua capacidade de produzir sem agredir/poluir o meio ambiente no exato momento de sua produção. Sabe-se dos impactos que a construção de uma usina hidrelétrica pode causar, porque qualquer que seja a extração de energia da natureza trará danos, seja para o clima, para os animais e o próprio ser humano, pois, não existe nenhuma forma de geração de energia 100\% limpa. Os primeiros impactos ambientais acontecem durante a implantação da obra, e, depois, para que a usina funcione é necessário um reservatório de água, consequentemente sua construção acaba afetando fortemente o clima, a fauna e flora locais. Neste sentido, este estudo tem como propósito identificar os impactos causados pela edificação da hidrelétrica de Itaipu para o meio ambiente, assim como, as políticas de compensação ambiental que vem sendo utilizadas. 
Hegemonia - Revista Eletrônica de Relações Internacionais do Centro Universitário Unieuro ISSN: 1809-1261

UNIEURO, Brasília, número 20, Janeiro-Junho de 2017, pp. 4-26.

Hidrelétrica de Itaipu Binacional: Alguns Antecedentes

Inaugurada em 1982, a Usina Hidrelétrica Itaipu Binacional surgiu com a promessa de gerar desenvolvimento nacional, principalmente para a região do Oeste do Paraná. No entanto, foi construída em uma área rica em biodiversidade e terras férteis para agricultura, deixando para trás enormes danos, não somente ao meio ambiente, mas a toda sociedade que se localizava no entorno, desde pequenos a medianos proprietários de terras que foram desalojados da área do lago, como várias comunidades indígenas. Fala-se de aproximadamente 60.000 pessoas que tiveram de deixar suas terras e casas para a implantação da hidrelétrica. Frente a essa situação, e como processo de compensação ambiental, Itaipu criou em 2003 o programa Cultivando Água Boa (CAB) que tem por fundamento a educação ambiental e a sustentabilidade como veículo de integração para uma possível consciência coletiva em torno do meio ambiente.

Tratar-se-ia de uma estratégia local de enfrentamento da crise ambiental global, em especial as mudanças climáticas, mas principalmente da sustentabilidade do território para melhorias das condições socioambientais da região. Desta forma, Itaipu tenta assumir a responsabilidade de impulsionar o desenvolvimento sustentável em torno de uma série de ações que compõem o Programa Cultivando Água Boa.

$\mathrm{O} C \mathrm{CAB}$ implantou vários programas num raio de ação de 29 municípios que formam fronteira com o lago, com área total de $8.000 \mathrm{~km}^{2}$.

O Programa Cultivando Água Boa, criado em 2003, reúne um conjunto de ações socioambientais da Itaipu e parceiros, executadas nos 29 municípios que compõem a Bacia do paraná 3 (BP3), no Oeste do Paraná. Em cada município, há um comitê gestor, com forte participação popular, uma das principais características do CAB. Hoje são 2 mil parceiros (prefeituras, órgãos públicos, empresas e a comunidade) atuando em uma área onde vivem mais de 1 milhão de habitantes ${ }^{3}$.

Pretende-se, neste trabalho, mostrar a forma como Itaipu, por meio do programa $\mathrm{CAB}$, busca promover a integração no contexto do desenvolvimento sustentável através das políticas de educação ambiental, tudo isso, tendo em vista a necessidade de se assumir uma responsabilidade compartilhada para compensar o histórico de danos socioambientais causados pela empresa ao meio ambiente nessa região.

${ }^{3}$ Disponível: Jornal do Programa Socioambiental da Itaipu Binacional. Cultivando Água Boa. Foz do Iguaçu - Março de 2015 - no 27, (p.5). Consulta: 18/12/2105. 
Hegemonia - Revista Eletrônica de Relações Internacionais do Centro Universitário Unieuro ISSN: 1809-1261

UNIEURO, Brasília, número 20, Janeiro-Junho de 2017, pp. 4-26.

Itaipu, Cultivando Água Boa, e a Integração Pela Interculturalidade

O tipo de integração que promove o $\mathrm{CAB}$ passa pelo encontro de diferentes comunidades pertencentes aos municípios raio de ação do projeto; são pessoas de diferentes classes sociais e níveis econômicos que confluem para trabalhar em torno do meio ambiente; estudantes de escolas e colégios, mulheres, homens, crianças, entre outros interessados no cuidado da água, das nascentes que formam a bacia do rio Paraná que abastece a hidrelétrica de Itaipu; diferentes culturas ou etnias, pois a região possui colonos de diferentes procedências e, inclusive, comunidades indígenas e quilombolas. Assim, notase tratar de um tipo de integração que apenas relaciona as pessoas em torno de determinados objetivos, sem ir mais além dessa possibilidade. O que autores, como Catherine Walsh, denominam interculturalidade relacional.

Entende-se por essa categoria, a forma como o Estado promove uma relação entre as culturas, mas sem questionar que existe uma cultura hegemônica. É utilizada pelas políticas de Estado para cumprir uma função de inserir os grupos humanos no mundo capitalista. Porém esta perspectiva omite o conflito de poder entre essas distintas culturas por conta do contato com as esferas políticas, econômicas e sociais. Trata-se de uma racionalidade capitalista do ponto de vista do Estado nacional. A interculturalidade relacional,

\begin{abstract}
hace referencia - de forma más básica y general - al contacto e intercambio entre culturas, es decir, entre personas, prácticas, saberes, valores y tradiciones culturales distintas, los que podrían darse en condiciones de igualdad o desigualdad. De esta manera, se asume que la interculturalidad es algo que siempre ha existido en este continente porque siempre ha existido el contacto y la relación entre los pueblos indígenas y afrodescendientes, por ejemplo, y la sociedad blanco-mestiza criolla, evidencia de la cual se puede observar en el mismo mestizaje, los sincretismos y las transculturaciones que forman parte central de la historia y "naturaleza" latinoamericana-caribeña, historia y "naturaleza" que siguen negando el racismo y las prácticas de la racialización, como también la diferencia vivida tanto por los pueblos indígenas como por los hijos de la diáspora africana. El hecho de que la "identidad nacional" se ha construido sobre esta dominación racial-relacional, complejiza más aún el assunto (WALSH, 2012, p. 63).
\end{abstract}

O CAB parte do princípio relacional, ou seja, a maneira como as diferentes culturas do Oeste do Paraná, ou dos 29 municípios em volta do lago da hidrelétrica, se relacionam harmonicamente desde tempos coloniais. Mais uma vez, as consequências da visão de cientistas sociais deixam suas pegadas na construção do imaginário social brasileiro, pois se acredita que a sociedade brasileira é democrática racialmente, lugar do encontro amigável das três raças desde a época da invasão ibérica ao território da América ou do Brasil 
Hegemonia - Revista Eletrônica de Relações Internacionais do Centro Universitário Unieuro ISSN: 1809-1261

UNIEURO, Brasília, número 20, Janeiro-Junho de 2017, pp. 4-26.

(FREYRE, 2006). O CAB coloca em andamento seus projetos para integrar pessoas e comunidades da região sem antes fazer uma análise crítica ao sistema que racializa e discrimina socialmente as diferentes culturas que aqui se cruzam. Ou seja, percebe-se que na região ainda continua prevalecendo os anseios da sociedade hegemônica, eurocentrada, por cima de outras culturas e etnias. Essa situação preocupa tendo em vista o pouco envolvimento e o não questionamento desse contexto pelo $\mathrm{CAB}$, quando divulga ao mundo o compromisso entre Itaipu, o meio ambiente e a sociedade.

Trata-se de um modelo de integração que também pode ser problematizado desde o ponto de vista da interculturalidade funcional; aquela onde o Estado reconhece que existem várias culturas, porém essas não se relacionam, pois não é de seu interesse que assim o façam. Dessa maneira, a interculturalidade baseia-se no reconhecimento da diversidade e diferença cultural com propósito de inclusão da mesma ao interior da estrutura social estabelecida.

\section{Desde esta perspectiva 'liberal' - que busca promover el diálogo, la convivencia y la tolerancia -, la interculturalidad es 'funcional' al sistema existente; no toca las causas de la asimetría y desigualdad social y cultural, ni tampoco 'cuestiona las reglas del juego' y por eso, 'es perfectamente compatible con la lógica del modelo neo-liberal existente' (WALSH, 2012, pp. 63-64).}

Nesse sentido, observa-se que o CAB se mantém como uma cortina de fumaça sobre os verdadeiros propósitos da hidrelétrica de Itaipu, ou seja, abertura total a aliança capitalista, pois a hidrelétrica alimenta grande porcentagem da maquinaria que sustenta empresas do tipo industrial, agrícola, pecuária, etc. Sabe-se que empresas, como as do agronegócio, contaminam o planeta e consumem água para manutenção do rigor do lucro, sem se importar com a "sustentabilidade". Os grandes empresários não estão interessados em que as pessoas em sua volta detectem que são manipuladas e usadas para fins capitalistas; no caso de Itaipu, essas pessoas acreditam firmemente que, junto ao $\mathrm{CAB}$, salvarão o planeta. Por isso acredita-se que o Programa Cultivando Água Boa promove um tipo de integração que é funcional ao sistema imperante, sem beneficiar o meio ambiente.

Dessa forma, pode-se inferir que o tipo de integração que vem sendo promovido pelo $\mathrm{CAB}$ não tem um caráter intercultural, crítico/decolonial ${ }^{4}$, projeto capaz de

\footnotetext{
${ }^{4}$ Entendemos com Anibal Quijano "la Colonialidad como uno de los elementos constitutivos y específicos del padrón mundial de poder capitalista. Se funda en la imposición de una clasificación racial/étnica de la población del mundo como una piedra angular del referido patrón de poder, y opera en cada uno de los planos, ámbitos y dimensiones, materiales y subjetivas de la existencia cotidiana y la escala social. Se origina y se mundializa a partir de América. Con la construcción de América en el mismo momento y en el mismo
} 
Hegemonia - Revista Eletrônica de Relações Internacionais do Centro Universitário Unieuro ISSN: 1809-1261

UNIEURO, Brasília, número 20, Janeiro-Junho de 2017, pp. 4-26.

transformar uma sociedade colonizada mental e culturalmente, retirando os preconceitos raciais, sexuais, de classe e de gênero para dar passo a uma sociedade menos conflitiva. Quando se trata do reconhecimento das culturas, a interculturalidade crítica vai além do reconhecimento da diversidade, do respeito e da tolerância da cultura do "outro", como retrata Catarine Wash. A autora diz que não basta reconhecer, respeitar e tolerar, a interculturalidade tem que ir além do reconhecimento da diversidade, do respeito e da tolerância (WALSH, 2012).

As políticas adotadas por Itaipu não confrontam as hierarquias de poder, nesta parte do Oeste do Paraná. A região tem um histórico de vários séculos de destruição, desde a época colonial quando era cruze de traficantes de escravos portugueses e de jesuítas que tentavam "salvar" os indígenas de suas "garras"; passando por um século XIX de invasão destas áreas por parte de fazendeiros e comerciantes de erva-mate e madeiras que escravizaram e dizimaram milhares de povos originários. Trata-se de uma região colonizada durante o século XX por famílias de origem italiana, polonesa e alemã que aqui se estabeleceram, se apoderando da terra que ainda possuíam os indígenas da região; sociedade relacionada com estigmas e prejuízos do sistema/mundo/colonial/moderno, que trabalhou para dar lugar a um dos territórios marcados pela disputa territorial entre grileiros, posseiros, indígenas e pequenos proprietários, conflito que posteriormente configuraria a grande propriedade apta para o desenvolvimento do agronegócio, em detrimento de áreas que foram indígenas e de pequenos proprietários obrigados a abandonarem o pouco que possuíam. Uma sociedade marcada pelo preconceito, o racismo, o machismo e a discriminação social.

Nesta região se implantou a Itaipu Binacional que trouxe como consequência vários dos problemas antes anotados. Portanto, não se acredita que CAB traga mudanças substanciais para esta parte do Paraná em termos de integração, pois difícil conciliar interesses políticos, econômicos e, principalmente, diferenças de cunho cultural onde impera uma visão moderna, racional, do progresso que vê em indígenas, pequenos proprietários, na agricultura familiar e nas comunidades quilombolas, o sinônimo do atraso.

movimiento histórico, el emergente poder capitalista se vuelve mundial, sus centros hegemónicos se localizan en las zonas situadas en el Atlántico - que después se identificarán como Europa-, y como ejes centrales de su nuevo sistema de dominación se establecen también la colonialidad y la modernidad. Con América Latina, el capitalismo se hace mundial, eurocentrado y la colonialidad y la modernidad se instalan, hasta hoy, como los ejes constitutivos de este específico sistema de poder" (QUIJANO, 2007, pp. 93-94). 
Hegemonia - Revista Eletrônica de Relações Internacionais do Centro Universitário Unieuro ISSN: 1809-1261

UNIEURO, Brasília, número 20, Janeiro-Junho de 2017, pp. 4-26.

Surgimento do Cultivando Água Boa (CAB)

Dentre todas as crises que o mundo contemporâneo precisa superar, a ambiental parece ser a mais emergente, tendo em vista seus efeitos devastadores para o meio ambiente e a sociedade. Os impactos socioambientais ligados aos recursos hídricos, principalmente as relacionadas a construções de barragens, provocam a degradação de biomas e ecossistemas. Esse fato, tem sido uma das grandes preocupações dos programas socioambientais que buscam a "sustentabilidade" objetivando a gestão ambiental para cuidar da água e da biodiversidade, principalmente, das regiões onde estão instaladas usinas hidrelétricas.

A Itaipu Binacional é a maior usina hidrelétrica em geração de energia do mundo. Localizada no rio Paraná, fronteira entre Brasil e o Paraguai, é responsável pela produção de quase $20 \%$ da energia consumida pelos brasileiros e $90 \%$ pelos paraguaios. A construção da hidrelétrica ocasionou deslocamento de pessoas dos dois lados da fronteira e submergiu no lago milhares de plantas e animais causando um desastre socioambiental de considerável envergadura. Pois, ao investir na geração de energia, gera também práticas indiscriminadas de poluição das águas, causando prejuízos ao meio ambiente e consequentemente à saúde humana.

Como medidas compensatórias, a Hidrelétrica de Itaipu, por meio de programas socioambientais, procura desenvolver ações para reparar danos causados no processo de construção e pós-construção da hidrelétrica. Nos discursos dos agentes diretores da empresa, muito mais que o propósito de gerar energia, essa construção geraria emprego e desenvolvimento tecnológico; estimulando o turismo, por conta do seu complexo setor empresarial.

A partir de 2003 a Itaipu Binacional promove uma mudança institucional que incorpora a responsabilidade socioambiental e o desenvolvimento sustentável aos objetivos estratégicos da empresa, em parceria com os inúmeros atores presentes nos municípios compreendidos pela Bacia do Paraná 3 (conjunto de microbacias conectadas com o lago da hidrelétrica). Desta maneira, teria ampliado sua missão empresarial através de programas educacionais integradores com o foco na qualidade de vida das pessoas e na "sustentabilidade" do meio ambiente. É nesse contexto que surge o programa Cultivando Água Boa que, segundo os dirigentes de Itaipu, retrata um novo conceito de responsabilidade socioambiental para estudar as implicações das mudanças ambientais e 
Hegemonia - Revista Eletrônica de Relações Internacionais do Centro Universitário Unieuro ISSN: 1809-1261

UNIEURO, Brasília, número 20, Janeiro-Junho de 2017, pp. 4-26.

climáticas no desenvolvimento da região para responder aos desafios provocados por essas modificações e seus impactos. O programa foi concebido e implementado à luz dos princípios contidos na Carta da Terra, especialmente, mas também é inspirado por outros documentos planetários, como Metas do Milênio, Agenda 21, Protocolo de Kyoto, Tratado de Educação Ambiental para Sociedades Sustentáveis e Responsabilidade Global, Documento Água para Todos - Água para a Vida, da UNESCO, Conferência Nacional de Meio Ambiente, Plano Nacional de Recursos Hídricos e nas Políticas Públicas do Governo Brasileiro $^{5}$.

São ações voltadas à quantidade e qualidade das águas; proteção, recuperação e conservação dos solos e da biodiversidade; melhoria dos fluxos ambientais, em sistemas de produção diversificados e limpos; na educação ambiental e na melhoria da qualidade de vida, principalmente dos segmentos socioambientalmente vulneráveis ${ }^{6}$.

O Programa Cultivando Água Boa significa um amplo conjunto de programas que têm na Educação Ambiental um de seus principais eixos, segundo o Informativo: Especial Educação Ambiental, Julho 2009. Assume-se, assim, o dever de construtores de uma Educação Ambiental na busca por soluções globais e locais. "O Cultivando Água Boa abrange 20 programas, 63 projetos/ações e mais de 2 mil parceiros, sendo desenvolvido nos 29 municípios da região de influência da hidrelétrica - a Bacia do Rio Paraná, parte 3 (BP3) -, onde residem mais de 1 milhão de habitantes".

Para conseguir cumprir com os objetivos propostos, o programa aqui referenciado acredita ser importante entrelaçar as questões ecológicas e ambientais para atingir uma conscientização socioambiental no aspecto da integração. No discurso, o CAB afirma ter provocado um verdadeiro movimento cultural, articulando e compartilhando esforços entre os diferentes setores que compõem o programa:

O Cultivando Água Boa é a estratégia que a Itaipu adotou para dar uma contribuição local ao enfrentamento das mudanças climáticas e demais desequilíbrios ambientais com o objetivo de adotar para si o papel de indutora de um verdadeiro movimento cultural rumo à sustentabilidade, articulando, compartilhando, somando esforços e dividindo responsabilidades com os diversos atores da BP3 em torno de uma série de programas e projetos interconectados de forma sistêmica e holística ("Planejamento, modelo de gestão e metodologia de implantação”. CAB+8 2003 a2010, p.9. A cursiva é nossa).

\footnotetext{
${ }^{5}$ Disponível: Informativo Cultivando Água Boa edição especial - 2014

http:/ / www.cultivandoaguaboa.com.br/sites/default/ files/iniciativa/Informativo $\% 20 \mathrm{CAB} \% 20 \mathrm{Ed} \% 20 \mathrm{Espec}$ ial\%20Carta\%20da\%20Terra\%202014.pdf (p. 3). Consulta: 01/12/2015.

${ }^{6} \mathrm{http}$ / / aguasdobrasil.org/edicao-05/itaipu-binacional-cultivando-agua-boa-mais-que-um-programa-umamobilizacao-regional.html. Consulta: 02/12/2015.

${ }^{7}$ http:/ /aguasdobrasil.org/edicao-05/itaipu-binacional-cultivando-agua-boa-mais-que-um-programa-umamobilizacao-regional.html. Consulta: 02/12/2015.
} 
Hegemonia - Revista Eletrônica de Relações Internacionais do Centro Universitário Unieuro ISSN: 1809-1261

UNIEURO, Brasília, número 20, Janeiro-Junho de 2017, pp. 4-26.

O Cultivando Água Boa tem vários projetos que estão presentes em toda a área de influência da hidrelétrica como os de Gestão por Bacias Hidrográficas, Plantas Medicinais, Agricultura Orgânica e Monitoramento Participativo, entre outros. O CAB teria o propósito de conscientizar as pessoas, numa verdadeira cruzada a favor da "sustentabilidade" e das questões socioambientais, por meio da educação ambiental; porém, mantêm o discurso a favor da multiplicação de barragens que, como se sabe, não contribuem com os objetivos traçados pelo programa, mostrando-se contraditórios.

Da mesma forma, o CAB cumpre para a Itaipu e o Estado brasileiro a função de vitrine da "sustentabilidade", assim como o neoliberalismo, desde os anos de 1970, construiu e promoveu suas próprias vitrines de progresso, tal como aconteceu com a projeção de países, como o Chile, vistos como modelos neoliberais a serem seguidos pelo resto dos países da América Latina. O que nos faz pensar no modelo de integração do CAB via educação ambiental e "sustentabilidade" como sendo funcional ao sistema capitalista. Neste sentido, faz-se necessário que as políticas de compensação ambiental promovidas pelo $\mathrm{CAB}$ sejam ética e coerentemente implantadas em favor do bem estar do maior número possível de pessoas.

CAB e o Discurso Sobre a Educação Ambiental Como Mudança Cultural e Libertária

Os programas do CAB são desenvolvidos na Bacia Hidrográfica do Paraná 3 e no entorno do Parque Nacional do Iguaçu, numa parceria com mais de 70 instituições, atuando com um Coletivo Educador que trabalha na construção e avaliação constantes da proposta; envolve diversos segmentos da sociedade em processos que, para o $\mathrm{CAB}$, seriam reflexivos, críticos e emancipatórios, num encontro de saberes que potencializaria o papel da educação nas mudanças culturais e sociais rumo à "sustentabilidade", por meio da metodologia Pesquisa-Ação- Participante (PAP), ou pessoas que aprendem participando. Atualmente são 221 educadores ambientais atuando com 2.983 prelecionadores populares, organizados em 119 comunidades de aprendizagem, ou círculos de alfabetização ecológica.

A Hidrelétrica de Itaipu, na busca pela promoção da "sustentabilidade", por meio da educação ambiental, realiza uma série de eventos, usando de personagens, artistas, intelectuais, dentre outros, para melhor cumprir seus objetivos. O CAB se conecta com o programa do Ministério de Meio Ambiente (2006) sobre Formação de Educadores Ambientais. Esta parceria consiste na potencialização de processos de formação de 
Hegemonia - Revista Eletrônica de Relações Internacionais do Centro Universitário Unieuro ISSN: 1809-1261

UNIEURO, Brasília, número 20, Janeiro-Junho de 2017, pp. 4-26.

educadoras e educadores ambientais, por intermédio do estabelecimento de articulações entre instituições que atuam com atividades socioambientais de caráter pedagógico ${ }^{8}$. Também é importante para o desenvolvimento dos objetivos do CAB a Rede formal de ensino e a Rede de Educação ambiental Linha Ecológica. São 130 mil estudantes da rede pública de ensino, nos 29 municípios, com potencial para desempenhar um papel educativo junto a suas famílias e comunidades. Entende-se que a Escola, veiculada pelo governo, sabe como promover ações em seu benefício, neste caso, em função do CAB. Além do papel do professorado, agentes mais participativos em benefício do meio ambiente. Também é importante anotar a forma como se promove a gastronomia, como mecanismo integrador do projeto, envolvendo cozinheiros e merendeiras, comprometidos com a utilização de produtos orgânicos. Assim, o CAB também promove - por meio da educação ambiental, uma melhor alimentação, livre de agrotóxicos.

Essas ações compreendem a capacitação de professores, distribuição de materiais didáticos, apresentações de teatro, formação continuada para nutricionistas e merendeiras e criação do $2^{\circ}$ Concurso de Receitas Saudáveis da BP3, com participação de 510 merendeiras, que resultou na seleção de 58 receitas para serem adotadas nas escolas e compiladas no $2^{\circ}$ Caderno de Receitas Saudáveis da BP3 - Edição Orgânicas9.

Destaca-se a Educação corporativa, educação ambiental voltada para o público interno da Itaipu. O objetivo é "promover a mudança cultural conectada à nova missão da empresa". Atualmente 50 facilitadores fazem parte da Rede Interna de Educadores, "estimulando a mudança de atitude em atividades cotidianas, como a coleta seletiva de lixo, a substituição de copos plásticos, o uso de papel reciclável, entre outras”. Outro programa é Educação ambiental nas estruturas educadoras, aqui se destaca o papel do Ecomuseu e do Refúgio Biológica Bela Vista, que visam desenvolver um tipo de educação voltada para as comunidades, estudantes e professores da região. Dessa forma, estas pessoas tornam-se assíduos desses projetos, onde se distorce a relação entre homens e mulheres com o meio ambiente - uma contradição das políticas socioeducativas do CAB -, pois se trabalha na perspectiva da relação entre seres humanos e animais em cativeiro. Por sua parte, o Ecomuseu promove uma ideia manipulável do tempo, da memória e da história desta região, onde indígenas aparecem representados como sendo parte da Idade da Pedra ou em

\footnotetext{
${ }^{8}$ Disponível: I Congreso Internacional de Educación Ambiental dos Países Lusófonos e Galicia, 24-27 setembro - Santiago de compostela. http://www.ceida.org/CD_CONGRESO_lus/documentacion_ea/comunicacions/EA_non_formal/Borstel Roesler_MarliRenate.html Consulta: 25/11/2015.

${ }^{9}$ Um novo modo de serpara a sustentabilidade. Metodologia e Resultados 2003-2009, p.9.
} 
Hegemonia - Revista Eletrônica de Relações Internacionais do Centro Universitário Unieuro ISSN: 1809-1261

UNIEURO, Brasília, número 20, Janeiro-Junho de 2017, pp. 4-26.

cemitérios, tal como os guaranis em urnas funerárias. O progresso, ligado a Itaipu e à energia elétrica são os protagonistas do Ecomuseo (LEDEZMA; CALAMBÁS, 2014).

Outra forma de promover a integração, entre comunidades e entre estas e o meio ambiente, é por meio da Educação nas Microbacias; em todas estas, a educação não-formal ocorre através das Oficinas de Futuro, que são inspiradas nos conceitos de Paulo Freire. Trata-se de "um diagnóstico participativo, em que a comunidade é estimulada a pensar sobre sua condição, imaginar o futuro que deseja e pôr em prática soluções para os problemas que enfrentam". No Cultivando Água Boa, essa prática foi batizada de Agenda 21 do Pedaço e é dividida em quatro etapas. A primeira delas é o Muro das Lamentações, em que toda a comunidade dialoga sobre os problemas socioambientais. Em seguida, passa-se para a segunda fase, a Árvore da Esperança, em que os participantes explicitam o que sonham para o lugar onde vivem. Na terceira etapa, o Caminho Adiante, são definidas as metas para as ações corretivas e, por fim, é celebrado um compromisso de cuidado com as águas, o Pacto das Águas, em que a comunidade, as lideranças e o poder público selam uma parceria em prol da "sustentabilidade".

Rituais propícios para o desenvolvimento de um estudo antropológico digno de ser realizado pelos funcionalistas e hermeneutas que tentaram, no século $\mathrm{XX}$, entender a mentalidade dos "primitivos". O CAB usa de intelectuais, como Paulo Freyre, e o modelo de educação por estes propostos, o que dá mais credibilidade ao projeto. Assim, entende-se que se cria um imaginário coletivo que integra, cujo eixo central é o meio ambiente, num ritual que coloca uma barreira nas mentes destas comunidades, impedindo entender o caráter das medidas compensatórias da Itaipu, a qual deixam a entender que não está preocupada com o meio ambiente e o planeta, mas sim com o cuidado das bacias que alimentam as águas do rio Paraná, pois, sem estas correntezas, a usina não funcionaria.

Observa-se, pelo descrito anteriormente, que o tipo de integração, é de caráter funcional, pois a Itaipu tenta promover a "sustentabilidade", ao tempo que luta a cada ano para superar o recorde de produção de energia para alimentar o capitalismo que depreda o meio ambiente. O problema é o da confiabilidade no programa CAB, pois a usina continua promovendo a construções de novas hidrelétricas.

O diretor-geral brasileiro de Itaipu, defendeu, na manhã desta terça-feira (14), em Foz do Iguaçu, a opção do governo federal pela construção de novas usinas hidrelétricas, como as dos rios Madeira, Tapajós e Xingu, na região Norte do 
Hegemonia - Revista Eletrônica de Relações Internacionais do Centro Universitário Unieuro ISSN: 1809-1261

UNIEURO, Brasília, número 20, Janeiro-Junho de 2017, pp. 4-26.

País. Para ele, os novos investimentos têm potencial para aliar desenvolvimento econômico e preservação do meio ambiente (Itaipu Binacional, 2011) ${ }^{10}$.

No que se refere à integração, o trabalho desenvolvido pelo CAB é também de caráter relacional, pois em nenhuma das fontes consultadas encontra-se formas de integração pela interculturalidade crítica, decolonial, como na definição de Catherine Walsh quando afirma que a interculturalidade é um projeto transformador que vai além de uma mudança do sistema; afirma que se trata de uma mudança de cultura, uma cultura civilizatória capaz de proporcionar o reconhecimento da diversidade, do respeito e da tolerância (WASH, 2008, p.140).

Assim, a integração que veem promovendo o CAB é preocupante, pois se insere na vida cotidiana, na vida privada das famílias para promover mudanças de atitude, do ser, do pensar. As comunidades, dessa forma, podem acabar incorporando que são culpadas pela crise planetária, pela contaminação ambiental. Sem que reste alguma forma de pensar sobre quem são os verdadeiros culpados pelos desastres ecológicos e sociais nunca antes sofridos na região, de consequências graves para o país e o mundo. O CAB precisa investir numa verdadeira integração, que derrube hierarquias, especialmente raciais, que predominam nesta região.

Cultivando Água Boa e a "Sustentabilidade"

O termo "desenvolvimento sustentável” surgiu a partir de estudos da Organização das Nações Unidas sobre as mudanças climáticas como uma resposta para a humanidade perante a crise social e ambiental pela qual o mundo passava a partir da segunda metade do século XX (BARBOSA, 2008, pp. 1-3). Com o intuito de unir países em torno do aperfeiçoamento de uma suposta "sustentabilidade" para o meio ambiente, em 1987, o conceito é introduzido pela WCED (World Commission on Environment and Development) ${ }^{11}$. Outra interpretação, mais atual, afirma que a "sustentabilidade" é a ideia

\footnotetext{
10 https://www.itaipu.gov.br/sala-de-imprensa/noticia/samek-defende-investimentos-em-novas-usinashidreletricas-no-pais Consulta: 22/02/2016.

11 Comissão Mundial sobre Meio Ambiente e Desenvolvimento, 1987. É um documento que considera a possibilidade de uma nova era de crescimento econômico, que deve ser baseada em políticas para sustentar e expandir a base de recursos ambientais. Acredita que esse crescimento seja absolutamente essencial para aliviar a pobreza. Crescimento que virá através de uma melhor tecnologia de gestão e organização social. É um relatório sobre o estado de assuntos globais, em termos de degradação ambiental, desigualdade econômica internacional e da pobreza, e da incapacidade das instituições nacionais e internacionais em vigor para lidar eficazmente com os desafios de garantir a equidade para o futuro das gerações. Fornece uma discussão útil da
} 
Hegemonia - Revista Eletrônica de Relações Internacionais do Centro Universitário Unieuro ISSN: 1809-1261

UNIEURO, Brasília, número 20, Janeiro-Junho de 2017, pp. 4-26.

de manutenção do equilíbrio em longo prazo - conservação sustentável -, de atender as premências do presente sem comprometer as possibilidades das gerações futuras de suprirem suas próprias necessidades (segundo o Relatório da Conferência das Nações Unidas (CNU) - também chamada de "Rio 92", responsável por consolidar as diretrizes para o socioambientalismo mundial). Além disso, de acordo com esse Relatório, o conceito está diretamente relacionado aos aspectos sociais, econômicos, ambientais e culturais da sociedade em geral, tendo como meta a continuidade do desenvolvimento, como o próprio nome sugere, de forma "sustentável", antes que a exploração dos recursos naturais cause o colapso total. Desta forma, desenvolvimento econômico, proteção ambiental e equidade social, são os princípios básicos a serem cumpridos pela agenda da CNU. É aquilo chamado de "conservacionismo", uma nova roupagem da "sustentabilidade". Basicamente, uma "sustentabilidade" contemporânea com os mesmos propósitos.

A eficiência da sustentabilidade está na sua possibilidade de aplicação a qualquer projeto ou empreendimento humano, independente do tamanho e da abrangência dele, visto que, para ser de fato sustentável, um projeto tem de abranger os pilares principais da sustentabilidade, sendo economicamente viável; socialmente justo; ecologicamente correto; culturalmente diversificado ${ }^{12}$.

Essa perspectiva cientifica positiva submete a natureza ao sistema-mundo-capitalistacolonial-moderno, onde a natureza passa a ser o combustível para o capitalismo, canalizando esse raciocínio da mercantilização da natureza através do discurso da "sustentabilidade". Argumentos como esses não podem servir de desculpas para legitimar a exploração do meio natural, e muito menos como forma de justiça/consciência social relativizada, como se os problemas com o meio ambiente estivessem a cargo da responsabilidade do cidadão comum que nada tem a ver com essa transferência de responsabilidades. A responsabilidade ambiental está inserida no âmbito macro do sistema/politico/capitalista. Nações hegemônicas industrializadas que exploram o meio ambiente de forma predatória para sustentar seu consumo capitalista buscam responsabilizar países "subdesenvolvidos" de forma igualitária na conservação do meio ambiente. Porém, uma coisa é certa, uma vez esgotados os recursos naturais, será impossível manter o "modelo civilizatório" ao qual estamos acostumados.

interconexão das mudanças económicas e ambientais, da interdependência das nações, tanto em termos económicos e ecológicos, e da interconexão dos sistemas ecológicos regionais. A Comissão conclui com recomendações para alcançar o desenvolvimento sustentável global. Disponível: http://public.wsu.edu/ susdev/WCED87.html Consulta: 27/11/2015.

${ }^{12} \mathrm{http:} /$ / www.fragmaq.com.br/blog/voce-sabe-o-que-e-sustentabilidade-ambiental/ Consulta: 30/11/2015. 
Hegemonia - Revista Eletrônica de Relações Internacionais do Centro Universitário Unieuro ISSN: 1809-1261

UNIEURO, Brasília, número 20, Janeiro-Junho de 2017, pp. 4-26.

Leonardo Boff retrata aquilo que pode se chamar de subterfúgio da ilusão, pois, em palavras do filósofo/teólogo "a maioria daquilo que vem anunciado como sustentável geralmente não o é”.

O que se pratica com mais frequência é o greenwash ("pintar de verde" para iludir o consumidor que busca produtos não quimicalizados). Por isso impõe-se senso crítico e uma compreensão mais apurada para saber o que é sustentabilidade e o que não é (BOFF, 2014, pp. 9-10).

Esse antagonismo difuso da lógica sustentável cientificista ocidental - que por um lado finge preocupa-se com a natureza, mas, na verdade, quer tirar o máximo de proveito possível da mesma para sustentar a própria demanda - já é contraditório na essência, porque, ao mesmo tempo protege e destrói o meio ambiente e toda sua biodiversidade. Essa "sustentabilidade" representada diante da crise socioambiental generalizada torna-se uma questão de vida ou morte, disse Leonardo Boff, que faz um histórico do referido conceito desde o século XVI até os dias atuais, submetendo a uma rigorosa crítica aos vários modelos existentes de desenvolvimento sustentável (BOFF, 2014).

Outra abordagem relevante, que introduz o foco da pesquisa, é a seguinte: que o Estado nacional é capitalista, não seria novidade, igual quando se sabe que este se relaciona com setores da elite para redefinir as formas e organização dos territórios e ditar regras para o meio ambiente e a população. Nesta compulsão pela exploração do meio ambiente, as empresas capitalistas, percebendo a importância das fontes de energia elétrica geradas pela exploração dos rios, em países como Brasil, investem na construção de hidrelétricas que fornecem energia para sustentar o sistema capitalista em detrimento do meio ambiente; dentre as quais, a Itaipu é um claro exemplo. Conforme reflexão de Guanães (2015): “Cada vez mais as politicas de estado se afinam com as politicas econômicas e com setores e grupos sociais específicos para redefinir as formas de organização dos seus territórios a partir de interesses e critérios ambientais, econômicos, culturais, civilizatórios". Quando se refere às formas de organização dos territórios a partir de interesses do capital, inevitavelmente o Estado, como representante legal da sociedade, tem a legitimidade de apropriação do território, pois o interesse econômico, tendo em vista a lógica mercadológica do "desenvolvimento sustentável", antecede os demais interesses. Sendo assim, a soberania territorial aplicada por alguns países em função do "progresso" e do "desenvolvimento" (para quem?) que permite beneficiar somente os interesses do capital financeiro, torna-se uma das válvulas de escape para a crise do setor privado. É o caso da Itaipu Binacional. 
Hegemonia - Revista Eletrônica de Relações Internacionais do Centro Universitário Unieuro ISSN: 1809-1261

UNIEURO, Brasília, número 20, Janeiro-Junho de 2017, pp. 4-26.

As hidrelétricas não fazem parte do rol da "sustentabilidade" consciente que enxerga a concepção sagrada típica dos povos originários que incorporam a natureza como parte do seu corpo, concepção totalmente diferente daquela mercantilista do "homem"branco-europeu-ocidental que submete a natureza a uma constante exploração. As hidrelétricas não garantem um socioambientalismo sustentável de fato, pois suas edificações destroem e degradam o meio ambiente comprometendo a qualidade do legado para gerações futuras.

Ruscheinsky retrata a sustentabilidade com o seguinte questionamento: "a nossa questão fundamental não é mais viver melhor amanhã, mas viver de modo diferente hoje, aqui e agora e para que isso aconteça exige profundas mudanças na forma de pensar, viver, produzir e consumir” (2003, p. 175).

Tal como no lema do Cultivando Água Boa: “O futuro no presente, para uma vida sustentável" (Agenda 21 do Pedaço, Itaipu).

Nos discursos dos representantes da empresa, desde sua formação, já dispunha de estudos e medidas de correção e conservação do meio ambiente. Em 1975 foi elaborado o plano básico de conservação do meio ambiente, com o objetivo de mitigar o impacto da formação do reservatório da usina ${ }^{13}$; em 1982- em consonância com a Política Nacional de Meio Ambiento do Brasil e as exigências legais do Paraguai -, Itaipu elaborou o Plano Diretor da Área do Reservatório, regulando seus usos múltiplos. Naquele ano, se deu a formação do reservatório, acompanhada pela operação Mymba Kuera (“Aqueles bichos”, em Guarani), que envolveu a mais de 200 pessoas e resgatou milhares de animais de diversas espécies da região. De 1983 a 2002, para conservar a flora e a fauna regionais e reduzir a erosão, a sedimentação e a contaminação do lago, Itaipu criou a Faixa de Proteção do Reservatório, coberta por uma área florestal com largura média de 200 metros e 2.900 quilômetros de extensão, além de nove refúgios e reservas biológicas que ocupam uma área de 40.031 hectares.

Na faixa de proteção, foram plantadas 40 milhões de árvores. Depois da fase de
construção da usina, foi elaborado e aprovado o Plano Diretor de Gestão
Ambiental, que, além de questões ambientais, considerou os fatores de
desenvolvimento socioeconômico. Ao início da produção de energia, em 1985,
também começou o pagamento de royalties aos municípios afetados pela
formação do reservatório. 2003 - Criado o Programa Cultivando Água Boa, a
partir da inclusão de conceitos de responsabilidade socioambiental na missão da
Itaipu, fundamento na gestão das microbacias hidrográficas do Rio Paraná 3
(margem brasileira) e na Bacia do Rio Carapá y Poti (margem paraguaia). É uma

${ }^{13}$ Sobre projetos ambientais antes do CAB, ou durante a construção da Itaipu, pode se consultar também a

(GAVAZZONI; GREGORY, 2012, pp.16-17). 
Hegemonia - Revista Eletrônica de Relações Internacionais do Centro Universitário Unieuro ISSN: 1809-1261

UNIEURO, Brasília, número 20, Janeiro-Junho de 2017, pp. 4-26.

resposta local para problemas globais (Informativo cultivando Água Boa, 2014, p. $3)^{14}$.

A Hidrelétrica de Itaipu, por meio do Cultivando Água Boa, insere-se no mundo dos pequenos e medianos proprietários que moram na fronteira com o lago da usina, para tratar de veicular suas mentes em torno da ideia do meio ambiente e da "sustentabilidade". Ações para a criação de uma "escola da vida", como tantas outras instituições escolares, que tem como objetivo a transformação dos corpos e das mentes, ao estilo das microfísicas do poder já estudadas por Michel Foucault. O programa CAB, afirma Relatório,

Estabelece uma estreita relação entre o desafio da sustentabilidade planetária,
com a realidade e a necessária ação local, a partir de uma visão sistêmica, integral
e integrada da relação do homem com seu meio, estabelecendo como novos
modos, o de ser, sentir, viver, produzir e consumir ${ }^{15}$.

Estabelece-se primeiro um decálogo de medidas pautadas em discursos globais sobre aquecimento do planeta e uma série de discursos que promovem um mal-estar na sociedade que acaba sendo culpada pelas mazelas que, na verdade, foi o capitalismo que causou na sua busca desenfreada pelo lucro. Hoje assiste-se às consequências desastrosas, mas que, segundo o discurso da "sustentabilidade" e da "modernidade", é o preço ou o sacrifício pelas vantagens da modernização. Escolas, colégios e universidades, além de produtores rurais com suas famílias, são envolvidos pelo CAB para, juntos, fazerem parte do escopo que pretende, a partir de uma visão sistêmica, integral e integrada da relação do "homem" com o meio ambiente promover uma nova forma de ser, sentir, viver, produzir e consumir. Ou seja, o CAB passa a cumprir o papel de um Estado totalitário frente à região Oeste do Paraná, pois por meio dessas medidas vai se inserindo na mente dos milhares de habitantes da comarca que, convencidos da culpabilidade dos estragos causados ao planeta, acabam cedendo a sua liberdade de movimento, de ação, frente às políticas ambientais da Itaipu. Entidade que se posiciona como independente do Brasil, se encerrando no seu campus para, desde sua soberania, promover estratégias que consigam transformar a mente das pessoas que, a pé firme, acreditam que o CAB é a salvação, e que fora desse programa e da Itaipu não há salvação para a região, para o país e para o mundo, pois Itaipu se promove como modelo de "sustentabilidade", de paradigma hidrelétrico na produção de energia limpa a nível planetário.

O programa promove a gestão por bacia hidrográfica (atua por bacia, sub-bacias e microbacias hidrográficas) de forma integral e integrada, com abordagem

\footnotetext{
14 http://www.boaspraticas.org.br/attachments/article/205/IT3000413KPORInformativo_bx.pdf Consulta: $03 / 01 / 2016$.

15 http:/ / aguasdobrasil.org/edicao-05/itaipu-binacional-cultivando-agua-boa-mais-que-um-programa-umamobilizacao-regional.html Consulta: 05/01/2016.
} 
Hegemonia - Revista Eletrônica de Relações Internacionais do Centro Universitário Unieuro ISSN: 1809-1261

UNIEURO, Brasília, número 20, Janeiro-Junho de 2017, pp. 4-26.

sistêmica, com amplo processo participativo, de cidadania, de responsabilidade compartilhada (envolve, numa enorme rede de parceiros, milhares de atores locais, quer econômicos, sociais, políticos, ambientais e culturais). Aplica o ciclo PDCA - planejar, executar, verificar/avaliar e agir/corrigir, e o grande papel da empresa - mais do que colocar recursos - é articular, compartilhar, somar esforços, dividir responsabilidades, um papel catalizador que identifica e envolve parcerias, constrói alianças estratégicas e promove sinergias de projetos e ações comprometidos com o desenvolvimento sustentável das respectivas territorialidades hídricas ${ }^{16}$.

Como afirma Ledezma (2014), sobre o meio ambiente, Itaipu se coloca também como guardiã e protetora das bacias do Paraná, do Prata e outras do Brasil. A empresa mobiliza as escolas, os bairros, as cidades em prol de seus projetos ambientais. Retira todo mundo das casas para levá-los a limpar beiras de rios, tirar o lixo de lotes baldios, fazer jardins, plantar árvores; tarefas nas que intervém homens, mulheres e crianças, anciãos, estudantes e professores.

Todos sintiéndose culpables por la contaminación ambiental; con esos trabajos creen pagar parte de la deuda que tienen con la humanidad y con el planeta. Ese sentiemiento de culpa es colocado por la Itaipu, interesada en que el agua fluya por todos los lados de la cuenca del Paraná y que nada amenace la producción de energía. La hidroeléctrica culpa a los habitantes de la región. Estos a su vez no perciben que la culpa principal es de la empresa por los estragos causados a la región, al medio ambiente y a la población en la época de la construcción. No perciben que los daños al medio ambiente se deben al sistema capitalista y a quienes se enriquecen a sus costas (LEDEZMA, 2014, p. 36).

Considerações Finais

A falsa ilusão de que o "homem" está preocupado com a natureza refletida no discurso da "sustentabilidade" é uma das várias maneiras de transferir responsabilidade do meio ambiente para todos; é o que se chama de lucros privados e prejuízos socializados onde apenas determinada parcela da sociedade se beneficia com a ideia conservacionista do meio ambiente. Estas questões integrando a problemática ambiental adaptada à gestão por bacias hidrográficas nos leva a uma reflexão sobre o aspecto sustentável do CAB que tenta transferir responsabilidades para quem não confere. A crise ambiental é definitiva, portanto, tem que ser objeto de preocupação daquele conjunto da sociedade que se beneficia com a exploração do meio ambiente. A responsabilidade ambiental não pode ser relativizada já que está inserida em um contexto capitalista mundial que não se relaciona diretamente com o cidadão comum. É fundamental, portanto, que os responsáveis pelas

\footnotetext{
${ }^{16}$ Disponível: Cultivando Água Boa: programa socioambiental da Itaipu e parceiros da BP3. http://www.cultivandoaguaboa.com.br/sites/default/files/iniciativa/BX_CAB_21x27cm_institucional.pdf Consulta: 08/01/2016.
} 
Hegemonia - Revista Eletrônica de Relações Internacionais do Centro Universitário Unieuro ISSN: 1809-1261

UNIEURO, Brasília, número 20, Janeiro-Junho de 2017, pp. 4-26.

políticas ambientais da região se preocupem com essas questões que terão que enfrentar, entendendo que são irreversíveis os danos já causados.

Pensar em uma harmonia socioambiental, tendo em vista o modelo de gestão das politicas ambientais baseado nas políticas globais revestidas de politicas sustentáveis para uma transformação que promova a ética na relação homens, mulheres e natureza através da Educação Ambiental requer, sobretudo, uma superação do modo de pensar, um rompimento das estruturas coloniais, de modo que haja questionamentos sobre modelos fracassados de gestão ambiental. Sabe-se que a Europa está na atualidade na sua segunda geração de floresta, então não é possível reproduzir essa lógica capitalista de políticas ambientais sustentáveis fracassadas.

Esse ambientalismo contraditório, promovido pela educação ambiental, reproduz os modelos padronizados de políticas ambientais globais. Mas, quando essas políticas ambientais são promovidas por meio da educação numa região vítima da modernidade, ou seja, da construção de uma hidrelétrica que exterminou plantas e animais e condenou ao deslocamento a 60 mil pessoas de ambos os lados da fronteira entre o Brasil e o Paraguai, enxerga-se que o discurso dos representantes de Itaipu, dista muito de ser satisfatório, onde se observa que, trata-se de distribuir as responsabilidades em pequenos focos, ou seja, desenvolvendo vários projetos para transferir responsabilidades de forma gradativa.

Verifica-se que a Itaipu, por meio de CAB, promove um belo trabalho que teria tudo para dar certo, pois convence a qualquer desprevenido da urgência da educação ambiental, dos cuidados com o meio ambiente, com o planeta e a humanidade, num discurso da "sustentabilidade" que promove integração entre pessoas e meio ambiente de 29 municípios que se localizam em volta da usina. Porém, não é possível acreditar num tipo de integração que promove uma ética entre cidadãos e meio ambiente, passando por cima do sacrifício que aconteceu na região há mais de 30 anos. Motivo pelo qual afirma-se que a integração promovida pela usina não é de caráter crítico, decolonial, pois existe uma grande distância entre sociedade e meio ambiente, onde este é considerado um elemento a ser explorado, e não uma parte que deveria ser incorporada ao ambiente social. Também porque a usina e o $\mathrm{CAB}$ não promovem uma interculturalidade que venha a criticar $\mathrm{O}$ modelo de sociedade altamente hierarquizado desta região do Paraná. Portanto, pensa-se que o tipo de integração seja de caráter relacional entre culturas e funcional para o Estado promotor deste tipo de integração. 
Hegemonia - Revista Eletrônica de Relações Internacionais do Centro Universitário Unieuro ISSN: 1809-1261

UNIEURO, Brasília, número 20, Janeiro-Junho de 2017, pp. 4-26.

Referências Bibliográficas

BARBOSA, Gisele Silva. “O Desafio do Desenvolvimento Sustentável”. Revista Visões. $4^{a}$ Edição, No 4, Volume 1 - jan/jun 2008.

BOFF, Leonardo. Sustentabilidade: o que é - o que não é. Petrópolis, RJ: Vozes, 2012.

COSTA, Bárbara Brena Santos; SANTOS, Géssica de Oliveira Santiago, et.al. "Licenciamento ambiental no Brasil sobre usinas hidrelétricas: um estudo de caso da usina de belo monte, no rio xingu (PA)". Cadernos de Graduação - Ciências Exatas e Tecnológicas | Sergipe | v. 1 | n.15 | p. 19-33 | out. 2012.

Cultivando Água Boa. Jornal do Programa Socioambiental da Itaipu Binacional. Foz do Iguaçu - mar. 2015 - n 27, (p.5). Consulta: 18/12/2015.

Cultivando Água Boa. Programa Socioambiental da Itaipu e Parceiros da BP3. Encontro Cultivando Água Boa - CAB 2014. Disponível em: http://www.cultivandoaguaboa.com.br/sites/default/files/iniciativa/BX_CAB_21x27cm _institucional.pdf

Cultivando Água Boa+8, 2003 a 2010. Redação e Edição: Divisão de Imprensa da Itaipu Binacional Apoio: Sônia Inês Vendrame (depoimentos das Comunidades Indígenas) e Vinícius Ortiz Camargo (textos Comunidades Indígenas, Jovem Jardineiro e Coleta Solidária) nov. $2010 . \quad$ Disponível: http://www.cultivandoaguaboa.com.br/sites/default/files/iniciativa/cab_caderno_atuali zado_nov2010.pdf Consultado: 25/12/2015.

Edição Especial Cultivando Água Boa. Informativo: “O Programa Socioambiental da Itaipu Binacional”. $\quad$ Edição $\quad$ - $2014 . \quad$ Disponível: http://www.cultivandoaguaboa.com.br/sites/default/files/iniciativa/Informativo\%20CA B\%20Ed\%20Especial\%20Carta\%20da\%20Terra\%202014.pdf Consultado: 27/12/2015.

FREIRE, Gilberto. Casa Grande \& Senzala: formação da familia brasileira sob o regime da economia patriarcal. 51. ed., SP: Global, 2006.

FRIEDRICH, Nelton. "Itaipu Binacional - Cultivando Água Boa - Mais que um programa: uma mobilização regional”. Disponível: http://aguasdobrasil.org/edicao05/itaipu-binacional-cultivando-agua-boa-mais-que-um-programa-uma-mobilizacaoregional.html Consultado: 22/12/2015. 
Hegemonia - Revista Eletrônica de Relações Internacionais do Centro Universitário Unieuro ISSN: 1809-1261

UNIEURO, Brasília, número 20, Janeiro-Junho de 2017, pp. 4-26.

GAVAZZONI, Edson Cláudio; GREGORY, Valdir. "CULTIVANDO ÁGUA BOA: possibilidade de um novo paradigma civilizatório". In: O professor PDE e os desafios da escola pública paranaense. Volume 1, Governo do Estado do paraná. Secretaria da Educação. S/D, 2012.

GUANAES, Senilde Alcântara. "Reflexões sobre territórios e politicas ambientais na América Latina". In: CRUZ, Clara; ARAÚJO, Nilson; CORAZZA, Gentil (org.). América Latina. Olhares e perspectivas. Florianópolis: Horizonte, 2015.

GUANAES, Senilde Alcântara. Aulas da disciplina de Culturas e Políticas Ambientais na América Latina do Programa de Mestrado em Integração contemporânea de América Latina (ICAL) na Universidade Federal da Integração Latino Americana. Segundo semestre, 2015.

http://www.cultivandoaguaboa.com.br/sites/default/ files/iniciativa/Informativo $\% 20 \mathrm{CA}$ B\%20Ed\%20Especial\%20Carta\%20da\%20Terra\%202014.pdf Consultado: 28/12/2015.

Instrução Normativa no 5 de 11/12/2006 / MMA - Ministério do Meio Ambiente (D.O.U. $13 / 12 / 2006)$

Itaipu Binacional, 2011, Samek defende investimentos em novas usinas hidrelétricas no País. Disponível: https://www.itaipu.gov.br/sala-de-imprensa/noticia/samek-defendeinvestimentos-em-novas-usinas-hidreletricas-no-pais Consultado: 29/12/2015.

Itaipu Binacional. Cultivando Água Boa. Um novo modo de ser para a sustentabilidade: Metodologia e Resultados 2003-2009, Foz do Iguaçu [s.n], 2009 b.

Itaipu Binacional. Informativo: Cultivando Água Boa. Especial Educação Ambiental, Julho 2009.

Jornal Cultivando Água Boa Edição no 13 (2º clichê). O programa socioambiental da Itaipu binacional. Foz. do Iguaçu, setembro de 2008.

KLIEMANN, Débora C.; SCHMITZ, Greicy D.; et. al. "Itaipu Binacional e o impacto ambiental na bacia do rio Paraná”. In: SMOLAREK, Solange Irene \& SMOLAREK DIAS, Bruno (orgs.). Planejamento urbano, regional e sócio-ambiental: visões de 2009, Cascavel: Smolarek Arquitetura, 2009.

LEDEZMA, Gerson. "Del “descubrimiento" y la conquista del Oeste del Paraná, hasta la construcción de Itaipu. La visión de tiempo de una sociedad eurocêntrica”. Sures. v. 1, n. 42014. 
Hegemonia - Revista Eletrônica de Relações Internacionais do Centro Universitário Unieuro ISSN: 1809-1261

UNIEURO, Brasília, número 20, Janeiro-Junho de 2017, pp. 4-26.

LEDEZMA, Gerson; CALAMBÁS, Licet. "Ecomuseo de Itaipu y Museo de la Tierra Guaraní: tiempo, historia y memoria en la frontera Paraguay y Brasil’. Sures, v. 1, n. 4, 2014.

LIMA, Perci. Foz do Iguaçu e sua bistória. Foz do Iguaçu: S/E, 2001.

Portal Itaipu: Cultivando Água Boa. Um programa da Itaipu Binacional e parceiros para as gerações de hoje e do futuro. Disponível em: http://www.cultivandoaguaboa.com.br/acao/nivel1/desenvolvimento-rural-sustentavel Consultado: 23/12/2015.

QUIJANO, Anibal. "Colonialidad del poder y clasificación social”. In: CASTROGÓMEZ, Santiago \& GROSFOGUEL, Ramón (editores). El giro decolonial. Reflexiones para una diversidad epistémica más allá del capitalismo global. Bogotá: Siglo del Hombre Editores/Universidad Central/ Instituto de Estudios Sociales Contemporáneos y Pontificia Uniuversidad Javeriana/Instituto Pensar, 2007, pp. 93-94.

RUSCHEINSKY, A. "Sustentabilidade e perspectivas da educação ambiental em nações subdesenvolvidas". In: LAMPERT, E. (Org.). Universidade na América Latina: Sustentabilidade, desafios e perspectivas. Pelotas: Seiva Publicações, 2003.

SALVALAGIO, Ana Rosa; ROESLER, Marli Renate von Borstel. Programa de Formação de Educadores Ambientais (FEA): "uma experiência concreta de educação ambiental”. Universidade Federal do Maranhão. Programa de pós-graduação em políticas públicas. III Jornada Internacional de Políticas Públicas questão social e desenvolvimento no século XXI. São Luís - MA, 28 a 30 de agosto 2007.

SANTOS, Ana Paula dos. "História oral y memoria: uma abordagem acerca da construção da hidrelétrica de Itaipu”. Patrimônio e Memória. Vol 1, número 2, 2005.

SOLER, Juan Pablo y URREA, Danilo. "Entre la inundación y el desplazamiento". In: Ecología Politica, Desplazados Ambientales. Número 33, 2007.

Violação dos Direitos Humanos na construção de barragens. Relatório da Comissão Especial. Atingidos por Barragens, do Conselho de Defesa dos Direitos da Pessoa Humana. Síntese. São Paulo, 2011.

WALSH, Catherine. "Interculturalidad y (de)colonialidad: Perspectivas críticas y políticas Visão Global”. Revista Visão Global. Joaçaba, v. 15, n. 1-2, p. 61-74, jan./dez. 2012. 
Artigo Inédito

Hegemonia - Revista Eletrônica de Relações Internacionais do Centro Universitário Unieuro ISSN: 1809-1261

UNIEURO, Brasília, número 20, Janeiro-Junho de 2017, pp. 4-26.

WALSH, Catherine. "Interculturalidad, pluralidad e decolonialidad: las insurgencias político-epistemicas de refundar o Estado". In: Tabula Rasa, vol. 9, 2008. 